\title{
CUTANEOUS THERMAL BURN AND OXIDANT-MEDIATED ACUTE LUNG INJURY: APPEARANCE IN SERUM OF LUNG-RELATED LDH ISOENZYME
}

\author{
Thomas M. AnNesley, Gerd O. Till, and Peter A. Ward \\ Department of Pathology, University of Michigan Medical School, 1315 Catherine Road, Ann Arbor, MI 48109, U.S.A.
}

(Received 19 July 1985; Revised 2 January 1986; Accepted 22 January 1986)

\begin{abstract}
Previous studies from our laboratory have demonstrated that thermal injury to the skin of rats is associated with the production of oxygen radicals by complement-activated blood neutrophils, resulting in acute lung injury as demonstrated by increases in lung vascular permeability and morphological evidence of vascular endothelial cell damage, interstitial edema, and alveolar hemorrhage. In the present study, the analysis of sera from thermally injured rats reveals an isoenzyme profile for lactate dehydrogenase (LDH;EC 1.1.1.27) that is compatible with origin from lung. The appearance of LDH-4 isoenzyme in serum of thermally injured rats correlates linearly with indices of lung damage, supporting the results of previous studies suggesting that thermal trauma to the skin can cause oxygen radical production by complement-activated blood neutrophils with resultant acute microvascular injury in the lung interstitium. Furthermore, interventions that protect from oxidant-mediated lung injury (catalase, scavengers of hydroxyl radical, iron chelators or neutrophil depletion) result in significant reductions in serum levels of the LDH-4 isoenzyme following thermal injury to the skin. Thus, measurements of LDH isoenzyme patterns in serum appear to be useful in monitoring tissue damage such as oxygen radical-mediated acute lung injury.
\end{abstract}

Keywords-Thermal injury, Lung injury, Lung-related LDH

\section{INTRODUCTION}

Systemic activation of the complement system has previously been demonstrated to be directly linked to the production of acute lung injury. The complement activation is associated with the appearance of $\mathrm{C5}$-related chemotactic activity in serum, activation of circulating neutrophils and the production of toxic oxygen-derived radicals which are the mediators responsible for damage of the lung vascular endothelial cells. ${ }^{1}$ This model depends on the generation of $\mathrm{H}_{2} \mathrm{O}_{2}$ and the presence of ionic iron, suggesting that the injury of pulmonary vascular endothelial cells may be due to the generation of hydroxyl radical (HO-). This tentative conclusion is supported by the protective actions of hydroxyl radical scavengers, dimethyl sulfoxide and dimethyl thiourea. ${ }^{2.3}$

Experimental models that have been utilized to study oxygen radical-mediated injury of lung include remote

Address correspondence to: Thomas M. Annesley, Ph.D., Department of Pathology, University of Michigan Medical School, 1315 Catherine Road, Ann Arbor, MI 48109, U.S.A. thermal injury of the skin, ${ }^{3.4}$ intravenous injection of cobra venom factor, ${ }^{1,2,5,6}$, and intravascular infusion of complement-activated plasma. ${ }^{7-11}$ Lung injury has been estimated qualitatively according to morphological changes observed by transmission electron microscopy, by the appearance, in lung and serum, of products of lipid peroxidation, and by changes in lung vascular permeability. In the present study, a marker of lung damage, an LDH isoenzyme, was measured in serum following thermal injury of the skin. The results demonstrate that coincident with the onset of acute lung injury there is a concurrent increase in serum of the lung associated LDH isoenzyme. The results further demonstrate a direct quantitative relationship between lung vascular permeability and LDH-4 content in serum, and a direct relationship between the serum content of LDH-4 and the plasma level of lipid peroxidation products. Interventional measures designed to protect the lung from oxygen radical-mediated injury were also associated with a significant decrease in the activity of LDH-4 relative to levels observed in unprotected animals. A direct relationship between the degree of pro- 
tection and the level of serum LDH-4 was found. These studies suggest that LDH isoenzyme activity may be useful in monitoring acute lung damage that results from the production of toxic oxygen radicals.

\section{METHODS}

\section{Animal model of thermal injury}

Pathogen-free Long-Evans rats (Charles River Laboratories, Portage, MI) were used in this study. Following anesthesia with ketamine hydrochloride (100 $\mathrm{mg} / \mathrm{kg}$ body weight) (Parke Davis, Morris Plains, NJ), the dorsal skin over the lumbosacral area was shaved and then exposed to $70^{\circ} \mathrm{C}$ water for $30 \mathrm{~s}$. Fluid resuscitation involved intraperitoneal injection of sterile saline immediately following thermal injury. Experimental animals were kept under anesthesia by additional treatment with ketamine for the three hour period until sacrifice by exsanguination from the posterior vena cava. Lung injury was determined by the use of transmission electron microscopy and by measurement of extravascular leakage of ${ }^{123}$ I-bovine serum albumin, as described elsewhere. ${ }^{1}$ Negative controls consisted of anesthetized but nonthermally injured rats.

\section{Intervention therapy}

In order to examine the relationship of hydroxyl radical to the onset of lung injury, scavengers of hydroxyl radical and iron chelators were evaluated for protective effects against lung injury following thermal injury. These agents included polyethylene-glycol-modified catalase (1200 U/kg intravenously) (Enzon Inc., Piscataway, $\mathrm{NJ}$ ), the hydroxyl radical scavengers dimethyl thiourea (1000 mg/kg intraperitoneally) (Alfa Products, Danvers, MA) and dimethyl sulfoxide $(1.5 \mathrm{ml} /$ $\mathrm{kg}$ intraperitoneally) (Fisher Scientific, Fair Lawn, NJ), and the iron chelator, deferoxamine mesylate $(15 \mathrm{mg} /$ $\mathrm{kg}$ intravenously) (Ciba-Geigy, Summit, NJ). Iron-saturated deferoxamine ( $90 \%$ saturation) was prepared by dissolving appropriate amounts of $\mathrm{FeCl}_{3}$ in an aqueous solution of deferoxamine. All agents were given $10 \mathrm{~min}$ prior to thermal injury.

\section{Lipid peroxidation products}

Lipid peroxidation products (conjugated dienes) were extracted from $1.0 \mathrm{ml}$ serum using $7.0 \mathrm{ml}$ of chloroform:methanol $(2: 1)$. The samples were stirred for 2 $\min$ at $45^{\circ} \mathrm{C}$, centrifuged for $5 \mathrm{~min}$ at $1000 \times \mathrm{g}$, and $5 \mathrm{ml}$ of the lower organic layer carefully removed. This was mixed with $2.0 \mathrm{ml}$ of distilled water that had been acidified to $\mathrm{pH} 2.5$ with $0.1 \mathrm{~N} \mathrm{HCl}$. Following vortex mixing and centrifugation as above, $2.5 \mathrm{ml}$ of the chlo- roform layer were removed and dried under nitrogen. The lipid residue was dissolved in $1.0 \mathrm{ml}$ heptane for spectrophotometric measurement at $233 \mathrm{~nm}$. Further procedural details can be found elsewhere.'

\section{Neutrophil depletion studies}

The depletion of circulating neutrophils $(<250 / \mu 1)$ was achieved by the use of intraperitoneal injection of a rabbit antiserum against rat neutrophils $(0.5 \mathrm{ml} / 100$ g) $18 \mathrm{~h}$ prior to thermal injury. ${ }^{1.13}$

\section{Serum samples}

Blood samples were obtained $3 \mathrm{~h}$ after thermal injury by aspiration from the posterior vena cava and allowed to clot at room temperature for $60 \mathrm{~min}$. The serum was separated by centrifugation and kept at $4^{\circ} \mathrm{C}$ until analysis, or stored at $-20^{\circ} \mathrm{C}$ for a period of less than one week. Except for lactate dehydrogenase (LDH) analysis, all measurements were made within $2 \mathrm{~h}$ after obtaining serum samples. We have evaluated rat tissue homogenates and spiked serums and have found that the $\mathrm{LDH}$ isoenzymes from rat are stable to storage at either $4^{\circ} \mathrm{C}$ or $-20^{\circ} \mathrm{C}$.

\section{Lactate dehydrogenase isoenzymes}

Total lactate dehydrogenase (LDH) was measured on a COBAS-Bio centrifugal analyzer (Roche Biomedical, Nutley, $\mathrm{NJ}$ ) using the kinetic procedure proposed by Gay $e t$ al.$^{14}$ The isoenzymes of LDH were separated by agarose gel electrophoresis (Beckman Paragon System, Beckman Instruments, Palo Alto, CA). Five microliters of specimen (or standardized dilution) were applied to the gel, followed by electrophoresis for 20 min at $100 \mathrm{~V}$. Isoenzyme bands were detected by linking the reaction of Gay et al. ${ }^{14}$ to the reduction of nitroblue tetrazolium chloride yielding a stable blue band for each isoenzyme of LDH. The activity of LDH-4 in sera from protected thermally injured animals was determined by densitometric scan using a Beckman CDS-200 densitometer, and referenced to the intensity of the LDH-4 band in sera from unprotected thermally injured rats.

\section{RESULTS}

Appearance of lung-associated $L D H$ isoenzymes in serum of thermally injured rats

A variety of rat tissues, organs, as well as neutrophils, erythrocytes and sera were analyzed in order to evaluate both the pattern and specificity of the LDH isoenzymes (Fig. 1). ${ }^{5}$ The tissues included kidney, liver, spleen, heart, muscle, brain, lung, skin, and erythro- 


\section{1 LIVER (1) II KIDNEY LUNG III HEART

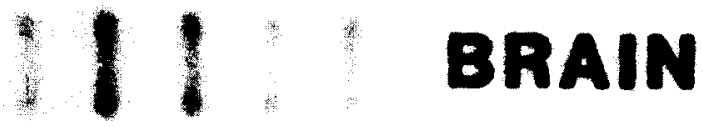

Fig. 1. Electrophoretic patterns of lactate dehydrogenase (LDH) isoenzymes present in homogenates of different organs or tissues. Anode is to the right. For further details see text.

cytes from untreated animals. As is demonstrated in Figure 1, normal sera, liver, muscle, neutrophils, skin, and erythrocytes contained essentially only LDH-5. Heart muscle and kidney contained large amounts of LDH-1 and 2, with LDH-1 greater than LDH-2 in the kidney. Lung contained a distinctive LDH isoenzyme pattern. Although the predominant isoenzyme was LDH-5, approximately $12 \%$ of the activity was $L D H-4$. There was minimal LDH-1, 2, or 3 in the lung homogenate. Thus, the lung appeared to have a fairly characteristic pattern.

The predominant pattern in the sera of thermally injured animals was LDH-4 and 5 (Fig. 2). Damage to cardiac, brain, or renal tissues would be expected to

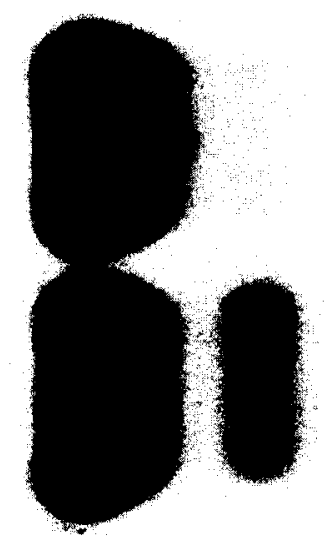

Fig. 2. Appearance of lung related LDH-4 isoenzyme in rat serum $3 \mathrm{~h}$ after thermal injury. Top, before injury; Bottom, post-injury. produce significant elevations in LDH-1, 2, and 3, but no increases in these isoenzymes were observed. Thus, the patterns observed in thermally injured rats revealed an isoenzyme pattern consistent with significant lung damage in these animals. The appearance in serum of LDH of lung origin correlates in a linear manner with increases in lung vascular permeability (Fig. 3).

\section{Effect of protection against lung injury on $\mathrm{LDH}-4$ in sera}

In previous studies, using cobra venom factor, it has been demonstrated that acute lung injury caused by intravascular complement activation could be greatly reduced through the protective action of iron chelators or hydroxyl radical scavengers. ${ }^{2}$ Pretreatment of thermally injured animals with the hydroxyl radical scavenger dimethyl thiourea (DMTU) or the iron chelator deferoxamine significantly reduced the extent of acute lung injury, as measured by both lung vascular permeability changes ${ }^{3}$ and appearance of the lung-associated enzyme LDH-4 (Table 1 and Fig. 3). Compared to untreated burn animals, the treatment with DMTU or deferoxamine reduced serum levels of LDH-4 activity by $68 \%$ and $57 \%$, respectively. This significant decrease in LDH-4 activity parallels the $77 \%$ and $75 \%$ protection determined from the results of lung vascular permeability studies (Fig. 3). In contrast to the protective effect afforded by deferoxamine, no protection was

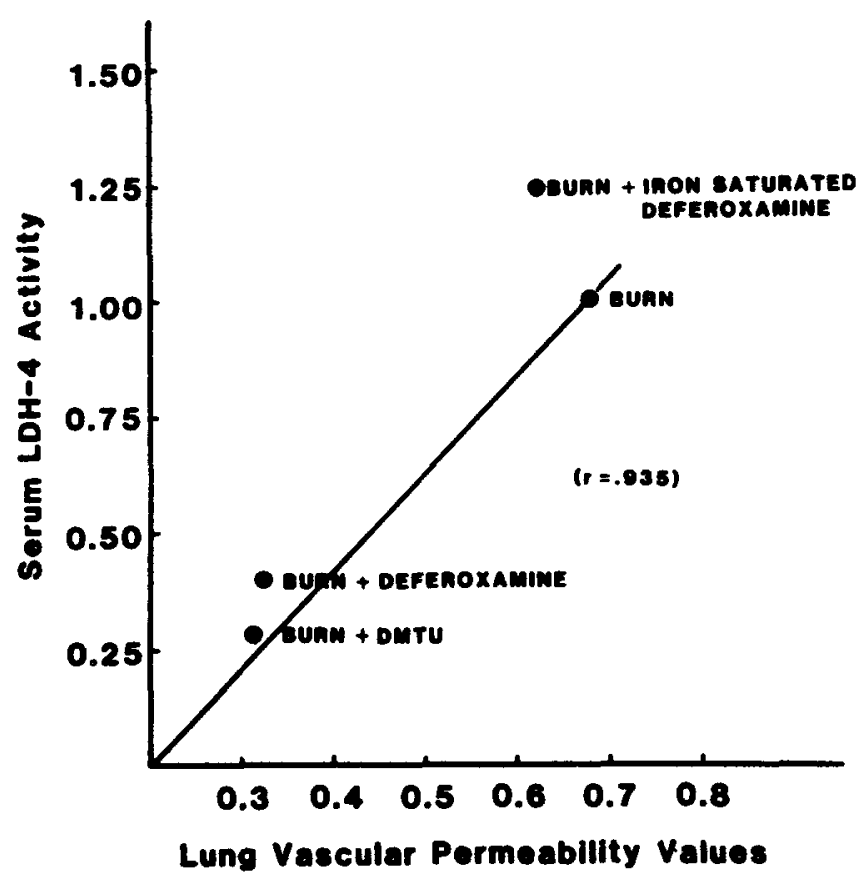

Fig. 3. Correlation between lung injury (measured as vascular permeability values) and relative LDH-4 activity in serum. 
Table 1. Effects of Iron Chelators and Scavengers of Hydroxyl Radical on Lung Injury and LDH-4 Activity in Serum 3 Hours After Skin Burns

\begin{tabular}{|c|c|c|c|c|c|c|}
\hline \multirow[b]{2}{*}{ Treatment } & \multicolumn{3}{|c|}{ Lung Damage } & \multicolumn{3}{|c|}{ LDH-4 Activity } \\
\hline & Mean \pm SEM & $\begin{array}{l}\text { Significance } \\
\text { (P value) }\end{array}$ & $\begin{array}{c}\text { Change } \\
(\%)\end{array}$ & Mean \pm SEM & $\begin{array}{l}\text { Significance } \\
\text { (P value) }\end{array}$ & $\begin{array}{c}\text { Change } \\
(\pi)\end{array}$ \\
\hline $\begin{array}{l}\text { None } \\
\text { Burn }\end{array}$ & $\begin{array}{l}0.20 \pm 0.01 \\
0.68 \pm 0.06\end{array}$ & & & $\begin{array}{l}0.01 \\
1.00\end{array}$ & & \\
\hline $\begin{array}{l}\text { Burn + Deferoxamine } \\
(15 \mathrm{mg} / \mathrm{kg})\end{array}$ & $0.31 \pm 0.01$ & $<.001$ & -75 & $0.43 \pm 0.11$ & $<.005$ & -57 \\
\hline $\begin{array}{l}\text { Burn + Iron-Saturated } \\
\text { Deferoxamine }(15 \mathrm{mg} / \mathrm{kg})\end{array}$ & $0.62 \pm 0.04$ & NS & -9 & $1.24 \pm 0.33$ & NS & +24 \\
\hline $\begin{array}{l}\text { Burn + DMTU' } \\
\quad(1000 \mathrm{mg} / \mathrm{kg})\end{array}$ & $0.31 \pm 0.03$ & $<.001$ & -73 & $0.32 \pm 0.07$ & $<.001$ & -68 \\
\hline $\begin{array}{c}\text { Bum + Catalase } \\
(1200 \mathrm{U} / \mathrm{kg})\end{array}$ & - & - & - & $0.33 \pm 0.03$ & $<.001$ & -67 \\
\hline $\begin{array}{l}\text { Burn + Neutrophil } \\
\text { Depletion }\end{array}$ & - & - & - & $0.32 \pm 0.11$ & $<.005$ & -68 \\
\hline
\end{tabular}

Expressed as changes in lung vascular permeability. Detailed information related to this data may be found in Ref. 3 .

'Expressed as ratio of serum $\mathrm{LDH}-4$ in test sample to serum $\mathrm{LDH}-4$ in bum only.

'Dimethyl thiourea.

'Polyethylene-glycol-modified catalase was injected 10 min prior to skin bum.

observed when iron-saturated deferoxamine was injected prior to thermal injury (Table 1). The injection of deferoxamine into control rats did not produce any change in the background values for lung vascular permeability. ${ }^{2}$ When iron-saturated deferoxamine was employed, an increase in LDH-4 activity by $24 \%$ was observed, suggesting augmentation of lung injury secondary to thermal burn. This effect may be explained by the additional availability of iron to function as a redox agent for the conversion of $\mathrm{H}_{2} \mathrm{O}_{2}$ to $\mathrm{HO}$.
The depletion of circulating neutrophils in thermally injured rats or pretreatment with catalase also reduced serum levels of the lung related isoenzyme LDH-4 (Table 1). These observations are in accord with previously published data indicating that neutrophil depletion or catalase treatment results in a reduction of lung vascular permeability in thermally injured rats. ${ }^{4}$ As expected, the marked reduction in LDH-4 shows a close relationship to the degree of protection resulting from these two experimental treatments.

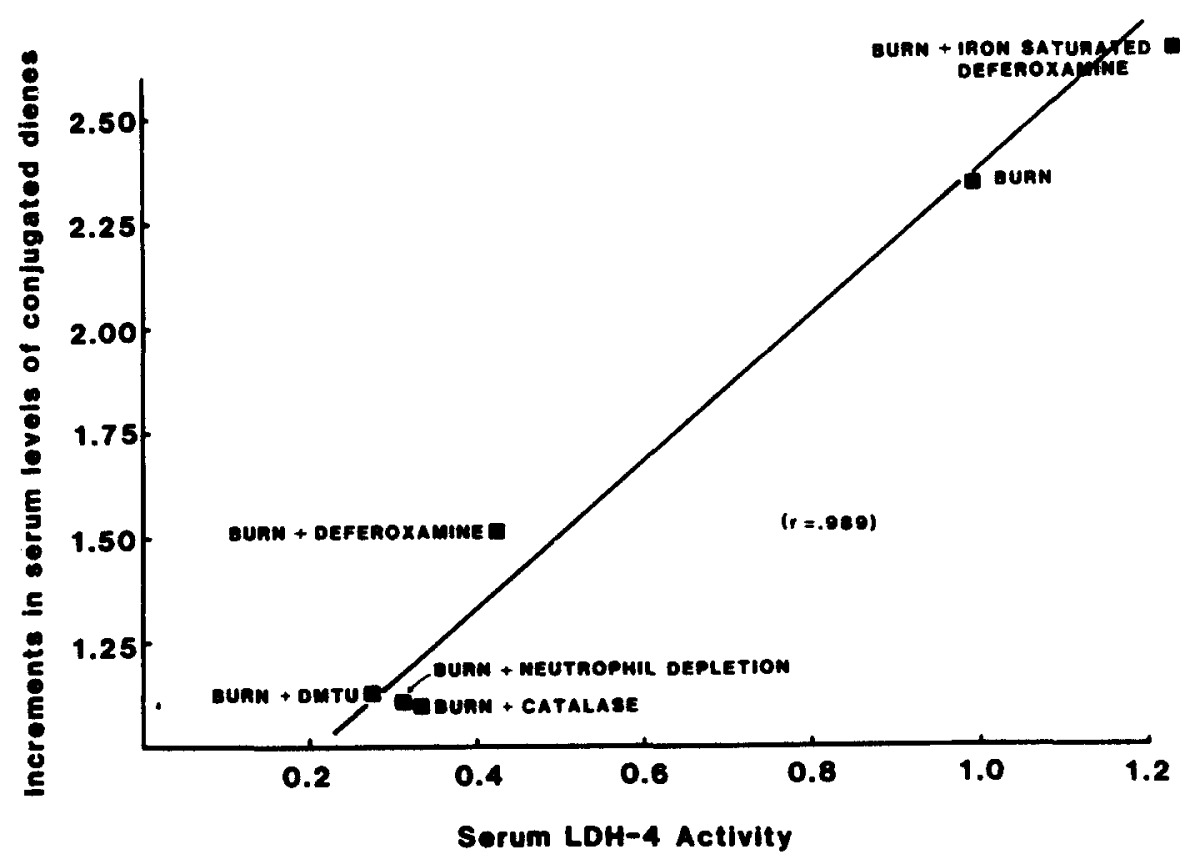

Fig. 4. Correlation between relative LDH-4 activity and serum concentration of conjugated dienes. 
Since lipid peroxidation has been implicated as a mechanism responsible for damage following tissue injury, ${ }^{3.5}$ we observed the relationship between LDH-4 activity and lipid peroxidation products following thermal injury. As demonstrated in Figure 4, a direct proportional relationship was obtained when LDH-4 was plotted versus the level of conjugated dienes in the sera of protected and unprotected thermally injured animals.

\section{DISCUSSION}

Thermal trauma to the skin has been demonstrated to be associated with the development of complement and neutrophil-dependent acute lung injury. ${ }^{4}$ This complement-mediated tissue injury has also been induced in an alternative model through the injection of cobra venom factor.' In both systems the degree of injury can be reduced by interventions with agents that act as hydroxyl radical scavengers or chelators of iron. ${ }^{2.3}$ In these studies lung injury has been estimated through the measurement of several factors, outlined below. In the presence of hydroxyl radical, lipid peroxidation may occur, resulting in the production of purported harmful agents. ${ }^{15,16}$ The lipid peroxidation products are estimated through the quantitation of conjugated dienes. Changes in lung permeability resulting from tissue damage are estimated by monitoring the leakage of radiolabeled bovine serum albumin into the extravascular compartment of the lung.

We describe here the proportional relationship between hydroxyl radical-mediated lung injury following skin burns and the level of a marker of lung damage, the lactate dehydrogenase isoenzyme $\mathrm{LDH}-4$. In parallel to the use of LDH isoenzymes in human disease, we have evaluated the LDH isoenzyme profiles of rat tissues, and have found the isoenzyme pattern detected in serum following thermal injury to match the profile observed in lung extracts. The leakage of LDH-4 from lung occurs as a direct consequence of acute lung injury, appearing in the circulation in an amount sufficient to be estimated electrophoretically. In a similar manner to the previous parameters that have been used to monitor lung damage, or protection from lung injury by interventional measures, LDH-4 activity correlates well with both changes in lung vascular permeability and lipid peroxidation products that appear as a result of acute lung damage.

The choice of $3 \mathrm{~h}$ measurements was made on the basis of several observations. Following thermal burn similar to that produced in this study, nearly all changes in lung permeability and reduction of serum complement occur within $3 \mathrm{~h} .{ }^{4}$ Additionally, following thermal injury the level of serum lipid peroxidation products, which quantitatively correlate with lung injury, ${ }^{5}$ peaks at approximately $3 \mathrm{~h} .^{17}$

The additional value of evaluating isoenzyme profiles following thermal injury is that it has revealed no changes in the first three isoenzymes of LDH, which would be suggestive of cardiac, cerebral, or renal damage. Thus an apparent specificity of organ damage (outside of damage to burned skin and muscle) exists early after burn. This is in agreement with the data presented in a previous report that showed the primary susceptibility of the lung to the damaging effects of oxygen radical from neutrophils following systemic activation of complement, using the ability to monitor plasma activities of the lung-related isoenzyme LDH- $4 .{ }^{5} \mathrm{Sim}$ ilar to the results reported here, in this prior study we demonstrated a direct relationship between lung injury and plasma levels of $\mathrm{LDH}, \mathrm{LDH}-4$, and conjugated dienes, as well as a significant drop in these parameters when interventional therapies were performed.

The direct linear relationship between serum LDH4 and the levels of conjugated dienes provides additional evidence that the conjugated dienes may result from lipid peroxidation occurring in lung vascular endothelial cells which show morphological evidence of injury. The LDH isoenzyme patterns observed in the thermally injured animals in our study demonstrated patterns consistent mainly with lung damage. No increases in other isoenzymes (i.e., LDH 1, 2, 3) was apparent. This does not rule out the possibility of damage to other organs but does suggest the lung to be more susceptible to oxygen radical produced injury during the early period following thermal injury to skin.

Increases in serum activities of enzymes following thermal injury have also been reported in one other study. ${ }^{17}$ In this study, following an initial increase in lipid peroxides, increases in the serum activities of glutamate oxalacetate transaminase, alkaline phosphatase, and lactate dehydrogenase were observed maximally at 2,14 , and 21 days respectively. The large differences in the appearance of these enzymes is most interesting in that it indicates that a pattern of delayed organ damage may exist following burn injuries. An evaluation of serum isoenzyme patterns or tissue morphology during this later period could provide more data related to this phenomenon.

In our present study and previous studies utilizing different models of acute lung damage, ${ }^{5}$ we have demonstrated the appearance of LDH-4 whenever acute pulmonary damage has occurred. In the oleic acid model of acute lung injury, ${ }^{5}$ LDH-4 appears in the serum as a result of damage to lung tissue, without an increase in the plasma level of conjugated dienes. This supports the theory that conjugated dienes appear as a result of only hydroxyl radical-mediated lung injury. These 
combined data further support the suggestion that acute lung injury resulting from thermal trauma to skin is related to hydroxyl radical production by neutrophils, resulting in the release of both $\mathrm{LDH}$ and lipid peroxidation products from damaged lung tissue. It is possible that the measurement of these parameters may be extended towards a useful application in human trauma or disease.

Acknowledgment--Supported in part by N.I.H. research grants HL28442, HL31963, GM28499, and GM29507.

\section{REFERENCES}

1. G. O. Till, K. J. Johnson, R. Kunkel, and P. A. Ward. Intravascular activation of complement and acute lung injury. Dependency on neutrophils and toxic oxygen metabolites. J. Clin. Invest. 69:1126-1135 (1982).

2. P. A. Ward, G. O. Till, R. Kunkel, and C. Beauchamp. Evidence for role of hydroxyl radical in complement and neutrophil-dependent tissue injury. J. Clin. Invest. 72:789-801 (1983)

3. G. O. Till, J. R. Hatherill, W. W. Tourtellotte, M. J. Lutz, and P. A. Ward. Lipid peroxidation and acute lung injury after thermal trauma to skin: Evidence of a role for hydroxyl radical. Amer. J. Pathol. 119:376-384 (1985).

4. G. O. Till, C. Beauchamp, D. Menapace, W. Tourtellotte, R. Kunkel, K. J. Johnson, and P. A. Ward. Oxygen radical dependent lung damage following thermal injury of rat skin. $J$. Trauma 23:269-277 (1983).

5. P. A. Ward, G. O. Till, J. R. Hatherill, T. M. Annesley, and R. Kunkel. Systemic complement activation, lung injury and products of lipid peroxidation. J. Clin. Invest. 76:517-527 (1985).

6. H. W. Tvedten, G. O. Till, and P. A. Ward. Mediators of lung injury in mice following systemic activation of complement. Amer. J. Pathol. 119:92-100 (1985).
7. D. C. Hohn. A. J. Meyers. S. T. Gherıi, A. Beckman. R. E. Morkison, and A. M. Chung. Productio. of acute pulmonary injury by leukocytes and activated complement. Surgerv 88:4858 (1980)

8. T. K. Bowers, A. L. Ozolins, N. B. Ratliff, H. S. Jacob, and D. E. Hammerschmidt. Hyperacute pulmonary vasculitis in rabbits receiving prolonged infusions of activated complement. $/ \mathrm{n}$ flammation 7:1-13 (1983).

9. S. Z. Perkowski, A. M. Havill. J. T. Flynn, and M. H. Gee Role of intrapulmonary release of eicosanoids and superoxide anion as mediators of pulmonary dysfunction and endothelial injury in sheep with intermittent complement activation. Circ. Res. 53:574-583 (1983).

10. B. O. Meyrick and K. L. Brigham. The effect of single infusion of zymosan-activated plasma on the pulmonary microcirculation of sheep. Structure-function relationships. Amer. J. Pathol. 114:32-45 (1984)

11. P. Sharkey, D. Judges, A. A. Driedger, H. Cheung. R. J. Finley and W. J. Sibbald. The effect of infusion of zymosan-activated plasma on hemodynamic and pulmonary function in sheep. Circ. Shock 12:79-93 (1984).

12. J. A. Buege and S. D. Aust. Microsomal lipid peroxidation. Methods Enzymol. 52:302-310 (1978).

13. K. J. Johnson and P. A. Ward. Acute immunologic pulmonary alveolitis. J. Clin. Invest. 54:349-357 (1974).

14. R. J. Gay, R. B. McComb. and G. N. Bowers. Optimum reaction conditions for human lactate dehydrogenase isoenzymes as they affect total lactate dehydrogenase activity. Clin. Chem. 14:740753 (1968).

15. A. L. Tappel. Lipid peroxidation and fluorescent molecular damage to membranes. In: Pathological Aspects of Cell Membranes (B. F. Trump and A. Arstilla, eds.), pp. 145-172, Academic Press, New York, (1972).

16. A. A. Noranka-Dutra, and E. M. Steen. Lipid peroxidation as a mechanism of injury in cardiac myocytes. Lab. Invest. 46:346353 (1982).

17. I. Nishigaki, M. Hagihara, M. Hiramatsu, Y. Izawa, and K. Yagi. Effect of thermal injury on lipid peroxide levels of rat. Biochem. Med. 24:185-189 (1980). 